Medicolegal

\title{
Whooping cough vaccine on trial again
}

\author{
CLARE DYER
}

A test case which could pave the way for more than 200 children and young adults to sue over alleged side effects of whooping cough vaccine started in the High Court on 5 October. The action, on behalf of 17 year old Susan Loveday, has taken the place of an earlier test case (Kinnear $v$ Wellcome and others), which collapsed in May 1986, when legal aid was withdrawn after the plaintiff's mother gave evidence which conflicted with the available medical records. ${ }^{1}$

Before the Kinnear case folded, at a cost of hundreds of thousands of pounds to the legal aid fund, the court heard five weeks of expert evidence from Dr Gordon Stewart, former professor of public health at the University of Glasgow, a leading critic of the government's mass whooping cough vaccination policy and a witness at a number of American trials over vaccine damage. ${ }^{2}$ This time round the case will have to be argued again from the beginning, though there are no plans to call Professor Stewart as a witness.

The adoptive mother of Susan Loveday, who is severely mentally handicapped, alleges that Dr George Renton, now of Bradford upon Avon, Wiltshire, was negligent in giving Susan diphtheria, tetanus, and pertussis triple vaccine in 1970 and 1971 . Her allegation is that, notwithstanding reactions to the first and second doses, which contraindicated further injections, the full course of three was completed. Dr Renton knew nothing of Susan's family history (she was the illegitimate daughter of a 16 year old mother). After her first injection she had a high temperature and local inflammation and was sleepy but crying a great deal. Her mother thought she was not as lively as before and later thought one eye seemed "odd." After the second injection she had a similar reaction and screamed all night. A month later she was observed to be slow in her development and was referred to a paediatrician, who reported that she looked "rather odd and is hypotonic" with, at $101 / 2$ months, a development level of 6 months. Shortly afterwards the third injection was given.

\section{Manufacturer a defendant}

In the Kinnear case Johnnie Kinnear had originally sued the Department of Health and Social Security and the vaccine's manufacturers, the Wellcome Foundation, as well as the doctor alleged to have administered the vaccine and the health authority responsible for the clinic where it was given. Legal aid to take Wellcome and the government to court was refused, but, in a highly unusual legal move, Wellcome asked and was allowed to stay in the case and, in fact, took over the conduct of the defence as far as the issue of causation was concerned.

Having so far spent some half a million pounds defending its vaccine's safety record, Wellcome is a defendant, along with the doctor, in the Loveday case, although this time the company has not been sued and, indeed, there is no evidence that the vaccine given to Susan Loveday was even manufactured by Wellcome. (There were

\section{London NW1}

CLARE DYER, BA, BLS, legal correspondent two other manufacturers in the market in the early 1970 s, Lister and Glaxo.) The company is in the case entirely at its own request and is once again conducting the defence on the issue of causation. Wellcome's leading counsel, Anthony Machin QC, emphasised on the opening day of the trial that the company was not seeking to prove the safety of the vaccine and, indeed, medically and scientifically, it would be quite impossible to do so, he said. Nevertheless, according to an affidavit by a company lawyer, the company believes "that there is no scientifically (or statistically) acceptable evidence that the vaccine causes permanent brain damage." Stanley Brodie QC, leading counsel for Susan Loveday, pointed out that the plaintiff was not claiming that the vaccine was unsafe but simply that it might be unsafe in certain specific cases when contraindications were plain.

\section{Two trials}

This time there is no danger of a repeat of the Kinnear debacle, because the judge, Mr Justice Stuart Smith, has agreed to a split trial. This first trial, which will probably last at least four months, will focus on just one issue: Can whooping cough vaccine cause brain damage? If the answer is "yes," the questions of whether it caused Susan Loveday's condition and whether her doctor was negligent will be reserved for a later trial.

Though not, strictly speaking, a product liability case-since there are no allegations of negligence against the manufacturer - the case is likely to be the first claim over drug side effects with a manufacturer as defendant to go to a judgment in a British court. Courts in the United States have made multimillion dollar awards against whooping cough vaccine manufacturers, but in the only case to reach a judgment so far in Britain-the Bonthrone case in Scotland-the manufacturer was not a defendant. Nine year old Richard Bonthrone lost his case against a doctor, nurse, and health board because the court was not satisfied that the vaccine had caused his condition. Wellcome is being sued in pending cases in Scotland and the Republic of Ireland, but writs issued in the English courts mainly name doctors and, in some cases, nurses and health authorities.

The trial, the costs of which are likely to top $£ 2 \mathrm{~m}$, will feature an impressive array of expert witnesses. The plaintiff's case suffered a setback when two key witnesses, Dr John Wilson of the Hospital for Sick Children, Great Ormond Street, and Professor David Miller of the Middlesex Hospital, expressed reluctance to appear on the plaintiff's behalf and sought to give their evidence as "amicus curiae" witnesses-assisting the court, rather than appearing for one of the parties. After their application was turned down by $\mathbf{M r}$ Justice Stuart Smith, however, they relented and agreed to appear for the plaintiff. Dr Wilson finished his evidence last week. He is a senior consultant neurologist at Great Ormond Street and a joint author of the Kulenkampff study of children believed to have suffered serious adverse reactions to diphtheria, tetanus, and pertussis triple vaccine, which sparked off the 1974 whooping cough vaccine scare. He told the court that in his opinion, from his 
own clinical experience and a series of case reports spanning over 50 years, there was strong circumstantial evidence suggesting a causal relation between immunisation with pertu'ssis vaccine and encephalopathic disease.

Following Dr Wilson the court heard from Dr John Menkes, professor of neurological paediatrics at the University of California, Los Angeles, who said that evidence that the vaccine can cause brain damage was incontrovertible. He added that since the 1960 s he had encountered more than two dozen cases of permanent brain damage, which, in his opinion, were caused by the vaccine.

\section{Expert witnesses}

As well as Professor David Miller, director of the national childhood encephalopathy study (which put the risk of serious permanent brain damage from the vaccine at one in 100000 children), other expert witnesses for the plaintiff will include $\mathrm{Dr}$ Herbert Barrie, paediatrician, Charing Cross Hospital; Professor L Steinman, paediatric neurologist, University of California, Los Angeles; Dr Wolfgang Ehrengut of Hamburg, who has written extensively on neurological complications after vaccination; $\mathrm{Dr}$ Martin Bellman, paediatrician, Bloomsbury Health Authority (one of the researchers for the national childhood encephalopathy study); Dr Richard Newton, paediatrician, Manchester; Professor David
Kerridge, statistician, Aberdeen; Dr Annette Dolphin, biochemist, St George's Hospital; Dr Peter Behan, neurologist, Glasgow; and Professor Ellsworthy Alvord, pathologist, Seattle.

Those expected to give evidence for Wellcome are: Dr Tom Pollock, former director of the Public Health Laboratory Service epidemiological research laboratory; Dr A H Griffiths, former deputy director of clinical research, Wellcome; Dr K D MacRae, medical statistician, Charing Cross Hospital; Dr John Stephenson, paediatric neurologist, Glasgow; Dr John Rees-Roberts, paediatric neurologist, Liverpool; Dr Richard Robinson, paediatric neurologist, Guy's Hospital; Professor Michael Bradbury, professor of physiology, King's College, London; Professor Alastair Wardlaw, professor of microbiology, Glasgow; Professor Anthony Dayan, professor of toxicology, St Bartholomew's Hospital; Dr James Ferrendelli, professor of clinical neuropharmacology, Washington University, St Louis, Missouri; Professor John Forfar, emeritus professor of child life and health, Edinburgh; and Dr Keith Redhead of the National Institute of Biological Standards and Controls.

\section{References}

1 Anonymous. Whooping cough case folds. Br Med $\mathcal{f}$ 1986;292:1400.

2 Anonymous. The law tries to decide whether whooping cough vaccine causes brain damage: Professor Gordon Stewart gives evidence. Br Med J 1986;292:1264-6.

\section{Medicine and the Media}

$\mathrm{D}^{\mathrm{s}}$ ESPITE BEING omitted from the BBC's recent retrospective of Dennis Potter's television series The Singing Detective refuses to lie down. It has been published, showered with awards, and even referred to obliquely in a television commercial for a well known newspaper-fame indeed.

Nobody who saw it, and few who did not, need to be reminded that its central character is struck down by an acute attack of psoriatic arthritis. Not only must he cope with the awful experience of the disease but also with dispiriting encounters with doctors in particular and hospitals in general. He finds himself hallucinating and feverishly going back over a lifetime of difficult experiences, first with his parents, then with his wife. As Potter puts it: "I felt myself being nudged into writing about the condition. Not what it's like to be ill, but what it's like to be a human being trying to understand the shape of your own life. And I used this man, humiliated by a very humiliating illness...." The BBC's make up department excelled itself in depicting the physical symptoms of psoriasis. Professional reviewers and general public alike had no doubts about their awfulness. "Hideously diseased," "horrific," "horrendous," "crippling and disfiguring," "shocking and disturbing," wrote the reviewers, turning to Fear adj in their Thesauri. The general public swelled the postbags of the newspapers, the BBC, and the Psoriasis Association.

The implications of all this for the popular conception of psoriasis have received only limited attention. Skin conditions like psoriasis are not well understood by the community. They evoke fears of infection, contagion, physical dirtiness, and moral culpability-as well as straightforward repulsion. The media's clear association of severe psoriasis with illicit sex on the one hand and decay and death on the other must hardly be good news for those forced to live with the disorder or trying to counter the stigma attached to it.

Further upmarket writers with more space wrestled with the "meaning" of Potter's serial, and as the going got tough the tough got psychological. The Observer (21 December 1986) thought the physical and emotional predicament in which Marlow found himself might be understood in terms of "an exploration of the nature and effects of guilt," especially "sexual guilt." The series is about Marlow's "... sexual guilt from witnessing his mother screwing a friend's father in a field; his guilt at her fate; his guilt at an incident at school; his guilt at his own skin disease and his guilt that his guilt might be the cause of it. All that guilt is buried into him by childhood trauma-luridly re-enacted in the sex scene, the scarecrow, the school mistress, the leering soldiers' faces-and then bores away into Philip's middle age, slowly corrupting and decaying both his mind and his body." The review goes on to suggest how as a result Marlow is "teetering on the brink of madness." From within, it all "... bubbles to the surface-all the guilt, pain, suppressed hate and suppressed love." As it does, however, "... so the surface, Marlow's surface, heals. Redemption is at hand."

The Listener (20 November 1986) repeated the theme of guilt commenting on the way in which Potter employed, "... the old Tin Pan Alley songs as a kind of psychoanalytical instrument of pilgrimage, working back through layers of memory, of regret, of guilt, and smothered fear." This profile, moreover, pointed to what its author Peter Lennon called "the equipment" which has shaped Potter's life and work, namely "... a kind of secular, religious fervour, an obsessional sexual guilt."

The "meaning" given by both Potter and his reviewers to psoriasis is one which serves to increase the stigma surrounding it. Far from being simply "sick," psoriasis sufferers live within a climate of culpability, even "evil." They and theirs have brought it on themselves.

In all this, following Potter's lead, reviewers have presented to their readers an understanding of psoriasis that is much at odds with the prevailing medical orthodoxy. The overwhelming emphasis on stress, psychosomatic causes, and personal responsibility is at variance with the current professional consensus. Dermatologists mostly dismiss a psychosomatic basis for the onset of psoriasis, even if they are slightly more tolerant of the suggestion that its course 